\title{
Genotipificação de isolados de Staphylococcus epidermidis provenientes de casos de mastite caprina
}

\author{
Genotyping Staphylococcus epidermidis isolated from mastitis in goats
}

\author{
Renata de Moraes Peixoto ${ }^{\mathrm{I} *}$ Rodolfo de Moraes Peixoto $^{\mathrm{II}}$ Kárita Cláudia Freitas Lidani $^{\mathrm{II}}$ \\ Mateus Matiuzzi da Costa ${ }^{\mathrm{I}}$
}

\section{- NOTA -}

\section{RESUMO}

Para verificar a dinâmica da resistência aos antimicrobianos em uma propriedade rural no município de Santa Maria da Boa Vista, PE, foram avaliados 14 isolados de Staphylococcus epidermidis de caprinos com mastite subclínica. O perfil de resistência aos antimicrobianos foi determinado pelo teste de difusão em disco. A genotipificação foi realizada empregando o marcador REP (Repetitive Extragenic Palindromic) - PCR, utilizando o primer RW3A, enquanto os graus de similaridade e o fenograma de agrupamento foram estabelecidos por meio do coeficiente de Sorensen-Dice $(S D)$ do algoritmo UPGMA, programa NTSYS$p c$, o qual permitiu a identificação de 4 padrões dos 14 isolados de S. epidermidis, sendo oito no perfil A, quatro no perfil B, um no perfil $C$ e um no perfil D. Para todos os grupos, a resistência à penicilina foi observada, enquanto que, para os grupos A e C, esta foi associada à lincomicina, no grupo B, esta foi associada à tetraciclina.

Palavras-chave: genotipagem, mastite, REP-PCR, Staphylococcus epidermidis.

\section{ABSTRACT}

To verify the dynamics of antimicrobial resistance in a property in Santa Maria da Boa Vista city - Pernambuco were evaluated 14 Staphylococcus epidermidis isolates from goats with subclinical mastitis. The profile of antimicrobial resistance was determined by disk diffusion test. The genotyping was performed using the marker REP (Repetitive Extragenic Palindromic) - PCR, using RW3A primer, where the degrees of similarity and clustering phenogram were established by means of the Sorensen-Dice coefficient (SD) algorithm UPGMA, program NTSYS-pc, which allowed the identification of 4 patterns of 14 S. epidermidis isolates, being eight in the profile $A$, four in a profile $B$, one in profile $C$ and one in profile $D$. For all groups to penicillin resistance was observed, while for groups $A$ and $C$ this was associated with lincomycin, for group $B$ this was associated with tetracycline.

Key words: genotyping, mastitis, REP-PCR, Staphylococcus epidermidis.

A caprinocultura leiteira tem crescido de forma significativa na agropecuária brasileira, conquistando novos mercados para o leite de cabra e seus derivados. Todavia, na região Nordeste (NE) do Brasil, a maior parte da produção é destinada à subsistência, sendo consumida próximo aos locais de produção (NOGUEIRA et al., 2008).

Dentre as doenças que mais afetam a qualidade do leite, destaca-se a mastite, que é a enfermidade mais importante em termos econômicos para a indústria leiteira. Essa doença é ocasionada por vários micro-organismos, particularmente de origem bacteriana, dentre eles, o $\boldsymbol{S}$ epidermidis, que está presente em diversos ambientes, além de fazer parte da microbiota de pessoas saudáveis, sendo responsável por infecções nosocomiais. Na glândula mamária, esse agente tem a capacidade de aumentar a contagem de células somáticas (CSS), diminuindo a produção e a qualidade do leite. Os processos moleculares envolvidos na patogenia da mastite e a especificidade dos hospedeiros são pouco compreendidos, mas presume-se que isso possa ser em decorrência, em

'Laboratório de Microbiologia e Imunologia Animal, Universidade Federal do Vale do São Francisco (UNIVASF), 56300-000, Petrolina, PE, Brasil. E-mail: renatavet_peixoto@hotmail.com. *Autor para correspondência.

"Instituto Federal de Educação, Ciência e Tecnologia Sertão Pernambucano, Campus Floresta, Floresta, PE, Brasil.

"'Laboratório de Imunopatologia Molecular, Universidade Federal do Paraná (UFPR), Curitiba, PR, Brasil. 
parte, das diferenças genéticas e variações alélicas entre as cepas (REINOSO et al., 2008). A identificação do agente etiológico da mastite é fundamental para determinar a patogenicidade e subsidiar a implantação de um programa de controle e prevenção desta enfermidade (CONTRERAS et al., 2007). Nesse sentido, objetivou-se avaliar a dinâmica da resistência de $S$. epidermidis aos antimicrobianos em uma propriedade rural no município de Santa Maria da Boa Vista, PE.

A coleta do leite e o diagnóstico da mastite foram realizados de acordo com os procedimentos sugeridos pelo National Mastitis Council (NMC, 2004). Não havia registro de antibioticoterapia prévia e os animais eram ordenhados manualmente, uma vez ao dia. Foram avaliados 14 isolados de Staphylococcus epidermidis, identificados por meio de suas características morfológicas, bioquímicas e tintoriais, de acordo com HOLT et al. (1994), bem como pelo sequenciamento do rDNA $16 \mathrm{~S}$. O perfil de resistência aos antimicrobianos foi determinado pelo teste de difusão em disco (CLSI, 2006), e as drogas testadas foram: gentamicina $(5 \mu \mathrm{g})$, estreptomicina $(10 \mu \mathrm{g})$, enrofloxacina $(5 \mu \mathrm{g})$, norfloxacina $(10 \mu \mathrm{g})$, ciprofloxacina $(30 \mu \mathrm{g})$, ácido nalidíxico $(30 \mu \mathrm{g})$, amoxacilina $(30 \mu \mathrm{g})$, oxacilina $(1 \mu \mathrm{g})$, doxiciclina $(30 \mu \mathrm{g})$, tetraciclina $(30 \mu \mathrm{g})$, eritromicina $(10 \mu \mathrm{g})$, lincomicina $(2 \mu \mathrm{g})$, rifampicina $(30 \mu \mathrm{g})$. Como controles para realização dos testes de sensibilidade aos antimicrobianos, foram utilizadas cepas de referência de Staphylococcus aureus (ATCC25923) e Escherichia coli (ATCC35218).

Para a caracterização molecular dos isolados, foi usado como iniciador o primer para REP-PCR, RW3A, com a sequência 5'TCGCTCAAAAACAACGACAC C 3' (DEL VECCHIO et al., 1995) e como template, oDNA foi termo-extraído, em água Mili-Q, conforme GRECO et al.
(2008), sendo que $2 \mathrm{~mL}$ (100ng $\left.\mathrm{mL}^{-1}\right)$ dessa suspensão foram aplicados em $48 \mathrm{~mL}$ do mix contendo $15 \mathrm{pmol}$ dos primers, 200mM dos desoxirribonucleotídeos, Tampão de Taq 1x e 5U de Taq (CENBIOT, UFRGS). Essa mistura foi levada ao termociclador e submetida a 35 ciclos constituídos de 30 segundos a $94^{\circ} \mathrm{C}, 30$ segundos na temperatura de anelamento de $54^{\circ} \mathrm{C}$ e 3 minutos a $72^{\circ} \mathrm{C}$. O resultado da PCR foi verificado em gel de agarose a $1 \%$, corado com brometo de etídio $\left(1,0 \mathrm{mg} \mathrm{mL}^{-1}\right)$ e documentado através do sistema de captura de imagem Kodak Digitalscience 1D.

Com o auxílio do software NTSYS, versão 2.02 (Numerical Taxonomy and Multivariate Analysis System) (ROHLF, 1993), foram construídas as matrizes de similaridade genética, utilizando código binário para a presença (1) ou ausência (0) de fragmentos amplificados para cada indivíduo, com base no cálculo do coeficiente de Sorensen-Dice (SD). A fim de representar graficamente o padrão de divergência genética com a matriz de similaridade, foi construído um fenograma com o algoritmo de agrupamento UPGMA (Unweighted Pair-Group Method Using an Arithmetic Average).

Os resultados das análises microbiológicas do leite demonstraram uma frequência de $23,8 \%$ de animais com a mastite subclínica. Quanto aos resultados da genotipificação, a técnica de REP PCR permitiu a visualização de quatro perfis, sendo que estes apresentaram fragmentos variando de 300 a 3000pb. Dessa forma, a análise do fenograma dos 14 isolados de $S$. epidermidis permitiu a separação de quatro acessos, sendo oito no perfil A, quatro no perfil $\mathrm{B}$, um no perfil $\mathrm{C}$ e um no perfil D. A similaridade entre os perfis genéticos dos isolados de $S$. epidermidis pode ser vista na figura 1 . Os perfis com maior similaridade

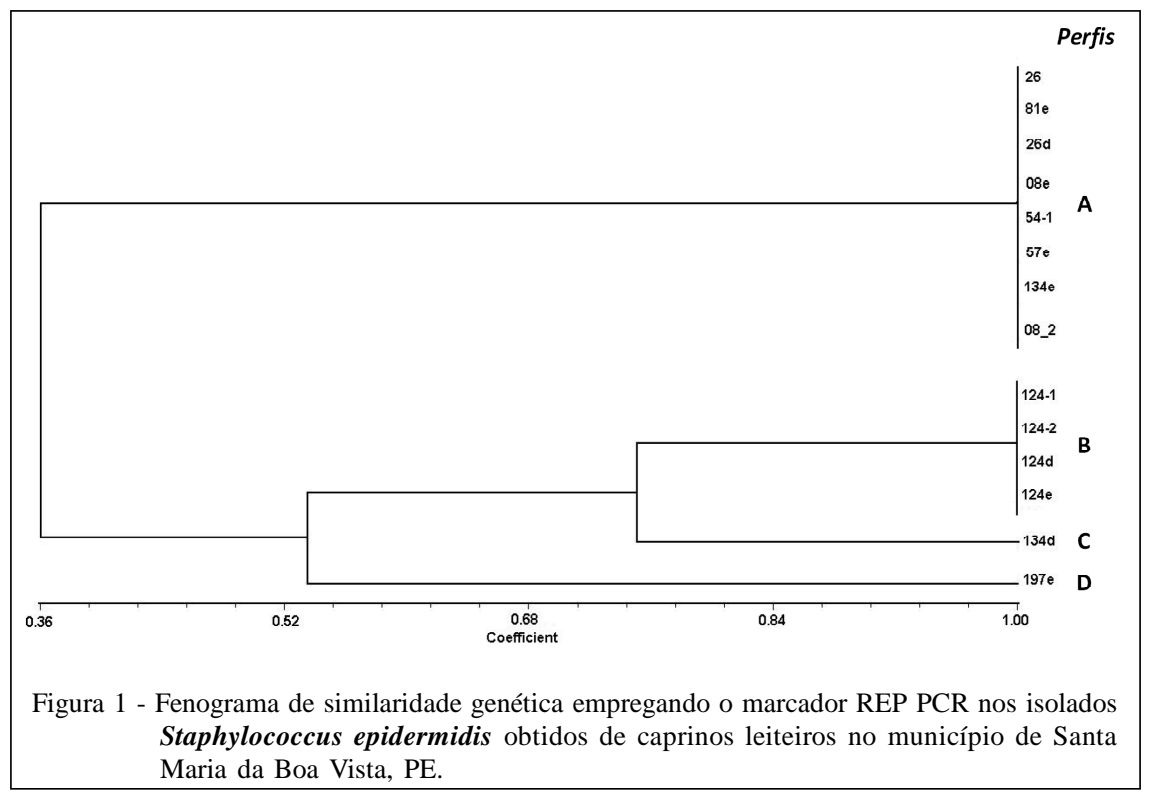

Ciência Rural, v.43, n.2, fev, 2013. 
foram C e D (85\%). Os perfis A e B foram os que demonstraram maior distanciamento genético dos demais, sendo diversos também entre si. Em outro trabalho, utilizando a técnica de REP PCR, REINOSO et al. (2008) trabalharam com amostras oriundas de humanos, bovinos e alimentos, sendo possível a separação de isolados de $\boldsymbol{S}$. aureus de humanos e bovinos. Da mesma forma, a grande variabilidade genética de isolados de Staphylococcus spp. coagulase negativa também foi comprovada pela técnica de eletroforese em campo pulsado em bovinos (SAWANT et al., 2009). Na comparação dos resultados da genotipificação com o perfil de sensibilidade aos antimicrobianos (Tabela 1), foi observado que o perfil $\mathrm{D}$ foi o único em que a multirresistência não foi observada. Para todos os grupos, a resistência à penicilina foi observada, enquanto que, para os grupos A e C, esta foi associada à lincomicina e, no grupo $\mathrm{B}$, esta foi associada à tetraciclina. De acordo com SAWANT et al. (2009), em S. epidermidis, a resistência a determinados grupos de antimicrobianos é fortemente associada a genótipos específicos.

Drogas antimicrobianas que apresentam indicação para espécie bovina são comumente empregadas no tratamento de infecções da glândula mamária nos pequenos ruminantes. É sabido que a dose e concentração desses antimicrobianos diferem entre as espécies, além disso, os agentes patogênicos também são variados. Dessa forma, este uso indiscriminado de

Tabela 1 - Relação entre o perfil genético e a resistência aos antimicrobianos de isolados de Staphylococcus epidermidis obtidos de caprinos leiteiros no município de Santa Maria da Boa Vista, PE.

\begin{tabular}{lcl}
\hline Isolado & Genótipo & \multicolumn{1}{c}{ Perfil de Resistência } \\
\hline 1 & A & ami, qui, beta, mac, lin \\
2 & A & ami, qui, beta, tet, mac, lin, rif \\
3 & A & qui, beta, tet, mac, lin \\
4 & A & qui, beta, tet, mac, lin \\
5 & A & ami, beta, tet, mac, lin \\
6 & A & ami, qui, beta, tet, lin \\
7 & A & qui, beta, tet, mac, lin \\
8 & A & ami, qui, beta, tet, mac, lin, rif \\
9 & B & ami, beta, tet, mac, lin \\
10 & B & ami, beta, tet, mac, lin \\
11 & B & ami, qui, beta, tet, mac, lin \\
12 & B & qui, beta, tet \\
13 & C & ami, qui, beta, tet, mac, lin \\
14 & D & mac \\
\hline
\end{tabular}

Em que: ami: amioglicosídeos; qui: quinolonas; beta: betalactâmicos; Mac: macrolídeos; lin: lincomicina; tet: tetraciclina; rif: rifampicina. antibióticos em explorações leiteiras pode levar à seleção e ao surgimento de estirpes bacterianas resistentes aos antibióticos (WALTHER et al., 2006).

A diversidade genética observada nos isolados de $\boldsymbol{S}$. epidermidis pode estar em parte associada com o padrão de resistência aos antimicrobianos. Dessa maneira, para manter a boa produtividade, é importante adquirir animais de propriedades idôneas e proporcionar um bom manejo sanitário, visando a evitar a ocorrência dessa doença.

\section{REFERÊNCIAS}

CLSI (Clinical and Laboratory Standard Institute). Methods for dilution antimicrobial susceptibility tests for bacteria that grow aerobically: approved standards. Wayne, Pennsylvania: CLSI, 2006. (Document CLSI M7-A7).

CONTRERAS, A. et al. Mastitis in small ruminants. Small Ruminant Research, v.68, p.145-163, 2007. Disponível em: $<$ http://www.sciencedirect.com/science/article/pii/ S0921448806002525>. Acesso em 02 mar. 2012. doi: 10.1016/ j.smallrumres.2006.09.011.

DEL VECCHIO, V.G. et al. Molecular genotyping of methicillin - Resistant Staphylococcus aureus via fluorophore - Enhanced repetitive - Sequence PCR. Journal of Clinical Microbiology, v.33, p.2141-2144, 1995. Disponível em: <http://www.ncbi.nlm.nih.gov/pmc/articles/PMC228351/pdf/ 332141.pdf>. Acesso em 02 mar. 2012.

GRECO, C. et al. Assessment of biofilm-forming ability of coagulase-negative staphylococci isolated from contaminated platelet preparations in Canada. Transfusion, v.48, p.969977, 2008. Disponível em: <http://onlinelibrary.wiley.com/doi/ 10.1111/j.1537-2995.2007.01631.x-i2/pdf >. Acesso em 04 mar. 2012. doi: 10.1111/j.1537-2995.2007.01631.x.

HOLT, T.G. et al. Irregular, nonsporing Gram - positive rods. In: _____ et al. (Eds). Bergeys's manual of determinative bacteriologogy. Baltimore: Williams and Wilkins, 1994. 593p.

NMC (NATIONAL MASTITIS COUNCIL). Microbiological procedures for the diagnosis of bovine udder infection and determination of milk quality. 4.ed. Verona: National Mastitis Council, 2004. 47p.

NOGUEIRA, D.M. et al. Passos para obtenção do leite de cabra com qualidade. Petrolina: Embrapa Semi-Árido, 2008. 6p. (Comunicado Técnico, 135).

REINOSO, E.B. et al. Genotyping of Staphylococcus aureus isolated from humans, bovine subclinical mastitis and food samples in Argentina. Microbiological Research, v.163, p.314-322, 2008. Disponível em: <http://www.sciencedirect.com/science/ article/pii/S094450130600067X>. Acesso em 04 mar 2012. doi: 10.1016/j.bbr.2011.03.031.

ROHLF F.J. NTSYS-PC: numerical taxonomy and multivariate analysis system, version 1.80. Steauket: Applied Biostatistics, 1993. 191p. 
SAWANT, A.A. et al. Antimicrobial susceptibility of coagulasenegative Staphylococcucs species isolated from bovine milk. Veterinary Microbiology, v.134, p.73-81, 2009. Disponível em: <http://www.sciencedirect.com/science/article/pii/ S0378113508003660>. Acesso em 04 mar. 2012. doi: 10.1016/ j.vetmic.2008.09.006.
WALTHER, B. et al. Methicillin-resistant Staphylococcus aureus (MRSA) in veterinary medicine: a "new emerging pathogen?" Berliner und Munchener Tierarztliche Wochenschrift, v.119, n.5-6, p.222-232, 2006. Disponível em: <http://www.ncbi.nlm.nih.gov/pubmed/16729469>. Acesso em 04 mar 2012. 